\title{
David Katz's Der Aufbau der Tastwelt (The world of touch): A synopsis ${ }^{1}$
}

\section{LESTER E. KRUEGER ${ }^{2}$ \\ HARVARD UNIVERSITY}

David Katz (1884-1953) has been cited as "one of this century's outstanding exponents of psychological phenomenology [Macleod, 1954, p. 1]." For Katz, the first task of the psychologist was "to observe and describe without bias both the calient characteristics and the subtle nuances of ordinary human experience [MacLeod, p. 3]." For Katz, "encouragement to deal with perceptual experience as legitimate facts of science came from the phenomenology of the philosopher Husserl [Amheim, 1953, p. 640]." Overall, in his sympathies, Katz "stood closest to the Gestalt theorists [MacLeod, p. 3]."

Katz's research covered a wide range, yet a "unity within Katz's apparent diversity of interest is to be found in his consistent application of the phenomenological method [MacLeod, pp. 2-3]." MacLeod noted that "the human hand as a unitary sense organ analogous to the eye, the composite photograph as a device for the study of group characteristics, the sensory basis of the phenomenon of elasticity, the phantom limb of the amputee, the ability of certain deaf people to appreciate music, and a host of other apparent byways of psychological investigation were opened up by Katz and redirected towards the central problem [p. 2]."

The present review focuses on Katz's (1925) Der Aufbau der Tastwelt (The World of Touch), which, it is hoped, will someday be available in English translation, as is now the case with Katz's (1935) classic, The World of Colour. In the meantime, the present review attempts to convey the highlights of Katz's work on touch to English readers. To facilitate access to Katz's monograph, most points discussed are accompanjed by page references, which, when presented alone, refer to Der Aufbau der Tastwelt. Brief quotations in English were translated by this reviewer.

\section{CONTEMPORARY RELEVANCE}

Katz is not being resurrected merely for historical interest. On many points, he is in surprisingly good accord with contemporary investigators. For example, there is Katz's concern about the low status of touch. Katz wished to dispel the invidious distinction, found in psychological texts of his day, which divided the senses into higher (e.g., vision, audition) and lower (e.g., touch), by showing how wondrous are the abilities of touch (p. viii). The fingers, as wielded by the hand, obtain information on the innards of objects, whereas the eye, remaining fixed on the outer surface of objects, plays a lesser role in developing the belief in the reality of the external world (pp. 5-6, 255-256). The elevation of touch to equal prominence with vision and audition has its contemporary spokesman in Geldard (1961, 1966, 1968). Where Katz studied the "language" of texture and hot and cold, Geldard has investigated what sorts of formal language the skin can handle. Geldard has found the skin quite capable of receiving rapid and sophisticated messages transmitted in vibratese (i.e., vibratory bursts varying in intensity, duration, body site). "One subject," Geldard reports, "was receiving at a rate twice that of proficient Morse reception [1968, p. 45]."

J. J. Gibson's (1966) book, The Senses Considered as Perceptual Systems, echoes many of Katz's major points. Both Katz and Gibson emphasize object perception and higher-order impressions, and both point out how the hand can be wielded, so that stimulation is obtained rather than imposed. For Gibson, the fact that wielding an object in different ways (tossing, shaking, etc.) produces a constant impression, indicates that "the merely proprio-specific information ... [is] filtered out, as it were, leaving pure information about the object [1966, p. 127]." The permanent properties of the object, the invariants over time, are isolated out from the flux of subjective sensations, and the perceiver "ordinarily pays no attention whatever to the flux of changing sensations $[1966$, p. 3$]$."

Katz, like some present investigators, noted links between touch and other modalities. Both Katz and Békésy (1967) depict a close correspondence between skin and ear (see further below). Recent work indicates that when information from vision and touch is in conflict, as when a person wears distorting goggles, vision dominates touch, and that when the conflict is prolonged, touch or the position sense, not vision, adapts so as to resolve the conflict (Rock \& Harris, 1967). Katz does not mention adaptation, but he does cite
Weber to the effect that the standard or scale used in judging an extent is that given by the eyes, and that what is given by the touch sense is reduced to the scale provided by vision (p. 240). Katz also describes an illusion that represents one more instance of "visual capture" (Gibson, 1933; Hay, Pick, \& Ikeda, 1965; Rock \& Harris, 1967). The "illusion is that in which, when one cuts some soft wood with a knife under a strong magnifying glass, the impression arises, as the result of the visual enlargement, that one is cutting deeply into a soft mass, such as cork [pp. 240-241, Footnote 4]."

Having noted Katz's contemporary relevance, let me outline what I feel are his three main points: (1) He deplores the typical atomism, with respect to both time and space, in the sensory psychology of touch, an atomism that bespeaks of a "tachistoscopic" mentality, and he emphasizes instead the higher-order impressions and gestalts that mark the contact between a person and the outside world of objects. (2) He regards movement of the touch organ (i.e., hand), relative to the object touched, as crucial in procuring tactile information. (3) $\mathrm{He}$ regards the sense of vibration as an important and sensitive modality, and one that is independent of the sense of pressure, though the two senses may share the same peripheral receptors; vibration, moreover, may provide the key as to why movement is so important.

The early, intimate association between psychologists and physiologists in the tactile sensory area, Katz feels, stunted the independent development of the psychological side. Katz acknowledges the yeoman service of the physiologists in delineating the peripheral receptors for touch, warmth, and cold, yet he argues that psychologists ought to be studying an entirely different realm of complex phenomena.

\section{SUBJECTTVE AND OBJECTIVE POLES OF EXPERIENCE}

The unfortunate overemphasis on anatomical elements came after Weber, with Blix's discovery of cold, warm, and pressure points (pp. 7-8), but the trend was aided by the existence of two distinct poles or aspects of the touch experience (p. 19): (1) the subjective pole (e.g., "I feel a 
prickling sensation"), to which the physiologists were attuned, and (2) the objective pole (e.g., "I feel a pointed object out there"), which Katz tries to bring out from the shadow of the physiologists. In vision, by contrast, only the objective pole exists, with all impressions being projected and felt "out there," even when one views an afterimage with the eyes shut or experiences a subjective gray which really depends on the state of the visual system rather than on an external object (p. 18).

In touch, while a person always has both types of imprescions (subjective and objective, or inner and outer), one pole may predominate at a particular moment. The subjective pole is stronger, for example, on parts of the body seldom used to obtain touch information, such as the inside of the nose or ear (p. 20). Movement is important: If a hand is moved to touch another part of the body, an objective impression obtains in the moving hand, but a subjective impression in the resting area being touched. Katz also cites Weber: "A special dissociation is shown when the warm hand touches the cold forehead; the warmth of the hand is felt quickly by the cold forehead, but the forehead is felt as an object [by the hand] [p. 20]."

A temperature sensation generally favors the subjective pole, and warm and cold may be experienced as pure states of one's body (p. 21). The temperature impression normally is not alone but is closely bound up with an impression of touch, especially on the fingers and inner hand and when the temperature is not too high or low. When the temperature sensation is separated from the embrace of the touch or tactile sensation, the subjective pole emerges strongly (p. 185). The subjective pole also is favored if the fingers are warmed or cooled by dipping them in water rather than by touching a solid object. The subjective pole is present almost exclusively in pain sensations. The emergence of the subjective pole also can be seen in psychopathological touch hallucinations as well as in the phantom-limb sensations of amputees (p. 53).

Another illustration of how movement affects the subjective-objective balance of a sensation is the Case of the Cold Foot. Keep a very cold foot absolutely motionless in bed, observes Katz (p. 182), and a painfully intense impression of cold arises, one that lacks form and is not localized on any part of the body. The impression has a free-floating and purely subjective character. The least movement of the foot, though, produces localization of the cold, and the person then possesses a "cold foot."
THE HAND AS TOUCH ORGAN

In addition to contrasting the subjective and objective poles, Katz also deviates from the sensory physiologists by. suggesting that the hand itself, rather than the minute receptors that the physiologists dig out, be regarded as the organ of touch. Katz could never produce in himself an imagined touch from which the touch organ was fully separated (p. 45). Other persons, when asked to reproduce an imagination of touching various materials, without exception concurrently imagined a touch organ, which almost always was the fingertips. In various tests, Katz consistently found that a person can recognize a material more rapidly and accurately by using five fingers rather than one (pp. 94, 134). Performance was as good when both hands participated in a simultaneous comparison as when a single hand made a successive comparison (p. 79).

The bridging of the gaps between fingers provides perhaps the most persuasive demonstration that the hand is a touch organ (pp. 94, 134). If you close your eyes, spread your fingers somewhat apart, then draw them over a surface, you will experience the surface as full and as extending into the area between the paths of the fingers. Katz had Ss move their fingers over smoked paper; when the Ss later saw the record thus obtained, they were surprised by how fragmentary were the strokes that had produced the impression of the surface. Regarding the hand as a touch organ is not so radical a notion, for in the eye, as Katz points out, the discrete individual receptors are spaced apart and even excluded entirely in the blind spot, so there must be considerable filling in of empty spaces to produce a continuous visual field (p. 40).

Another example of filling in occurs when the bristles of a stiff brush are moved over the skin, so that only the points of the brush touch the skin. A person feels only these points, yet, in another sense, also "feels" the spaces in between the bristle points. The person experiences not a tactile nothingness between the points but merely touch-space that is empty and not covered with material (p. 42). The phenomenon can be likened to the visual figure-ground relationship, with the bristle points as figure and the empty spaces as ground, though Katz reports that he was never able to reverse the tactile figure-ground relationship so as to change the momentary figure into the ground.

Further proof against the overconcern with the local signs from the individual, minute receptors comes from the manner in which an object retains its form and qualities even when moved from the hand to less sensitive areas which, if they had received the object first, would not have yielded the same impression and recognition (p. 170). Katz regards such persistence as analogous to memory-color in vision. The fingers, being very sensitive to the richness of the tactile domain, provide a memory image for other areas of the body; the fingers provide the "official" version of how some material ought to be imagined to feel (p. 47). So potent is the memory-image created by the fingers, the imagined touch on less sensitive areas of the body gives a clearer impression than does actual touch (p. 51).

A somewhat related phenomenon is the "tactile afterimage": If you move your hand over a material and then suddenly stop, the impression of the material may persist while the hand is at rest, even though the impression would never have arisen if the hand had been at rest initially and had never moved (p. 50). While you move your hand and arm over an object, not only does the impression persist as the object moves to less sensitive areas of the arm, but also the object maintains its identity qua object, as successive sets of fixed individual receptors are triggered, and is felt to maintain a constant position in space as the arm glides by it (p. 69).

\section{THE MODES OF TOUCH}

Katz describes modes of touch that are quite analogous to the film-, surface-, and volume-color modes described in The World of Colour (Katz, 1935). Conceiving an analogue in touch to surface-color is not difficult, since surface-touch is readily experienced when one touches an object made of some fixed material such as metal, glass, or wood (p. 26). In surface-touch the perceiver experiences a definite surfice, at a definite distance, and at a definite orientation.

But what touch experience could be imagined that would correspond to film-color, whose foggy, spongy appearance, produced by homogeneous illumination, contrasts sharply with the hard, impenetrable, and definitely localizable appearance of surface-color? Directing a strong (and sufficiently rapid) stream of air or liquid, Katz finds, produces film-touch or spaciffilling sensation (raumfullendes Tastquale). The stream feels indeterminate as to form, and, though the suggestion of a certain thickness may arise, the "form" lacks a rear boundary and always is percejived as lying in the frontal-parallel plane. Film-touch does not represent the qualities of a body; it characterizes a material, not an object. In film-touch, the resistance that the material offers the hand is experienced 
as elastic rather than as stiff or rigid (p. 29). The subjective pole is stronger in film-touch than in surface-touch (p. 28).

Volume-touch occurs when a person feels a solid object through a soft material, and the soft material seems to fill space (naumhafte Tastphanomene). Try this yourself by laying a blanket over a matchbox or book. To arouse the feeling of transparency, which is crucial for volume-touch, the solid object must have sharp contours; merely putting the blanket on a flat surface, such as the floor, does not produce volume-touch (p. 30). The ability to feel two layers at the same time aids the physician, who, by means of palpation, can feel organs through the skin. The physician, of course, directs his attention to the organ itself and ignores the voluminous feel of the intervening tissue. When a person wears gloves, he feels a surface lying beyond a thin covering layer. With close-fitting, very thin rubber gloves, the impression of a veiling layer may give way to the impression of "deafness" in the fingers (p. 32).

Transparency may persist even when the intervening material is rigid. When asked to discriminate between various papers by writing on them, Katz's Ss projected or localized the impressions of hardness and softness at the writing point of the pencil rather than in the hand holding the pencil (p. 105). Katz also notes Lotze's observation that when a person touches an object with a stick, the person feels he is in immediate contact with the object, just as though his hand were actually touching it (pp. 115-116). Lotze also remarked that "while sewing, our perception seems to be imrinediately present in the point of the needle (p. 116)." By the same principle of extepnal projection, Katz notes, an automobile driver feels the goodness of the road and an airplane pilot feels the elastic qualities of the air rather than merely the local juggling of a steering wheel or rudder against the hand.

\section{THE ROLE OF MOVEMENT}

Witely resting the hand on a material may suffice to evoke a simple impression of uurface-touch, but to feel modifications of the surface (hardness, graininess, etc.) and thes to recognize the specific material, movement is necessury. For Katz, movethent obtains its power largely through its production of the vital ensitions of vibration (p. 231). The pressure sense determines the presence of the surface, whereas the vibration sense deteithines the modifications of the surface (pp.'235-236). The vibration sense is discussed further below.

The role of movement differs considerably for vision and touch. In vision, movement generally impedes perception of qualities, yet in touch, it is lack of movement that is most damaging (pp. 43, 71). "The visual things with their colors as well as their macromorphic and micromorphic qualities are only accessible to the resting eye. The reverse situation holds for touch [p. 71]." The touch organ, when at rest relative to external objects, is beset with a partial anesthesia. Movement is as indispensable to touch as light is to vision (p. 58). "Movement appears to be necessary even for the perception of oiliness [p. 58]."

The importance of movement in touch goes against the grain of physiological atomism, with respect not only to space, but also time, because it indicates that information is integrated over a short duration rather than a single instant (p. 56). Ironically, apparent movement may influence findings even of atomistically inclined sensory psychologists, as when the two-point limen is reduced by stimulating two points successively rather than simultaneously (p. 60).

In the felt impression of the object, though, movement, time, and space leave no trace of themselves (pp. 63-64); the object impression is precipitated as an independent perception, largely uncontaminated by its journey through tactile space and time. Even so simple a quality as roughness bears no trace of movement in its contents. For elasticity, however, the opposite case holds (see below).

Even in vision, some movement is necessary, as shown by the rapid fading and disappearance of a stabilized retinal image. In touch, Katz found that adaptation occurs quickly for the resting touch organ, yet never seems to occur when movement is present (pp.61, $125-127,206)$. The rapid adaptation in the absence of movement makes us largely unaware of the clothes we wear, whereas "if one moves, for example, a rotating disk with a cloth band over the finger tips with moderate speed and moderate pressure, then it can be done for minutes-indeed, for hours, if one can only muster the necessary patience for the endeavour-without one being able to establish with certainty any essential change in the touch impression [p.61]."

Is there a preferred way of moving the hand in taking in information? Katz measured how fast Ss moved their hands back and forth, towards and away from the body, while trying to recognize a flat-lying material. One of Katz's three Ss moved his hand outward and inward at the same speed, but the other two Ss showed a slow outward and a rapid inward motion (p. 155). All three Ss said the movement towards the body was more important for their judgments. The outward movement generated less friction, was observed to a much lesser degree, and may have served merely as a necessary precondition for the occurrence of the inward movement.

\section{THE VIBRATION SENSE}

Let us now tum to the vibration sense, which looms large in Katz's monograph. Pressure is a near-sense, whereas vibration has many of the capabilities of a far-sense (p. 211). Vibration of the ground, for example, may signal the imminent approach of a train or a herd of buffalo. Our world, Katz contends, is not merely a world of sound, but, in a wider sense, it is even a world of vibration (p. 213).

Katz is inclined to pair the vibration sense with hearing, as two dynamic senses, and to pair the pressure sense with vision, as two static senses. The dynamic arising wid falling away present in vibrations and tunes is lacking in pressure and colors (pp. 209-210). More than a superficial sinularity may exist between the vibration sense and hearing, because the sense of vibration may represent a way-station on the evolutionary path that led from the sense of touch to that of hearing (p. 211). In animals, sensations of vibration to oscillating stimuli preceded sensations of sound. Weber, too, had commented on the connection between vibration and sound (p. 198). (For more recent research tracing similarities between ear and skin, see Békésy, 1967.)

The structures in the skin seem as well constituted to transmit information from oscillation as do the structures in the basilar membrane of the ear (p. 219). Vibrations on the skin are perceived only in the 50- to $500-\mathrm{Hz}$ range (p. 201), which is a situation much more like that of the ear, which is sensitive to 20 to $20,000 \mathrm{~Hz}$, than the eye, for which there is only one boundary value, above which fusion occurs for all flicker frequencies (p. 200).

Is there an analogue in touch to the qualitative distinction between pure acoustic tones and noise? Katz found that the rough vibration produced by a special apparatus led to a less fine, less orderly, and less pleasing sensation than the vibration produced by a tuning fork (p. 208). Further, the latency of arousal was much longer for the tuning-fork vibration.

Katz cites the ability of deaf persons to "Yisten" to music through skin vibrations as further evidence of a close connection between skin and ear. Katz's evidence is suspect, however, because the intense vibrations produced in concert halls might reach an intact inner ear in a deaf person through bone conduction. In any case, Katz mentions Helen Keller's enjoyment of 
music (p. 192) and relates a fascinatung tale of Herr Sutermeister, a prominent deaf-mute, who late in life discovered that he could enjoy music (pp. 194-196). Sutermeister could appreciate different qualities of music, such as bright and somber, and seeing the conductor and the musicians aided his perception. The orchestra had to be situated on a podium, though, because if it were not, the oscillations would be transmitted along the floor to his feet and thereby produce a disagreeable feeling that upset his inner harmony (p. 195). Transmission through the hand also was ineffective and unpleasant. The main reception point for pleasant music was the thorax or chest (pp. 195, 207).

Deaf persons are very sensitive to vibrations, as indicated by the aid they receive, in learning to speak, by putting their fingers on their own or another person's throat or larynx (pp. 191-192). Such sensitivity indicates that the vibration sense in the fingers is not much inferior to the ear in sensory-motor aspects (p. 196). One deaf girl could understand what a normal girl was saying in a dark room, if she laid her hand on the breast of the speaking girl (p. 191). Another deaf person could "listen" to and understand vibrations transmitted from the speaking person by means of a billiard stick or a bowed piece of paper. Again, however, bone conduction to an intact inner ear might explain such sensitivity.

Katz felt that though the vibration and pressure senses share the same set of peripheral receptors on the skin, the two represent different modalities. The pressure sense does not provide the raw materials, the parts, which go to form a gestalt-like whole in a vibration; no pressure "parts" are recognizable as such in the "whole," so such "parts" do not exist for the skin or ear (pp. 222-223). Vibration, then, is no mere off-shoot or modification of the pressure sensation, but something qualitatively different. Katz thus denies the validity of Müller's principle of specific nerve energy, which holds that each nerve produces a specific conscious quality when excited (p. 222).

Katz gives several examples of how felt vibration and pressure differ. When he had Ss turn their hand palm up, so that the fingernail rather than the fingertip touched the material, he nevertheless found good recognition of the material (p. 113). Using the fingernail presumably excluded the pressure sensation. When a person pulls an iron nail across a rough surface, vibrations arise in the lower arm as well as in the hand, indicating the resonance capacity of the lower arm, and, again, excluding the possibility of a pressure sensation (pp. 227-228). Similarly, if the elbow is placed against a tuning fork, vibrations, but no pressure sensations at all, are felt in the hand (pp. 202-203). The pressure sense also can be excluded by holding a stick between the teeth and moving it across a piece of material; this leads to vibrations and quite accurate judgments as to the material "touched" (p. 122).

A vibration sensation does not arise if one touches a tuning fork very briefly, say for half a second, indicating a longer latency for vibration than pressure sensations (p. 203). A thousandfold variation in the physical pressure of the tuning fork on the skin has no clear effect on the vibration sensation (p. 204). Energetically rubbing a finger, such as with a band of pearls, may temporarily raise the threshold for pressure by an enormous amount, while hardly affecting the threshold for vibration (p. 206).

What initially may have turned Katz from the pressure to the vibration sensation is the great sensitivity his Ss exhibited to differences in the smoothness of paper and other planular materials, a sensitivity shown for the lips and toes as well as the fingers (pp. 114-120, 143). Katz's Ss readily discriminated whether or not two sheets of paper were uniform in surface texture, even when the papers did not differ enough to have produced different pressure sensations (pp. 107, 112, 234). Performance was surprisingly good when blindfolded $\mathrm{Ss}$ made absolute judgments of what they were touching and what material it was (e.g., wood, glass, metal, cloth). Differences in heat transfer and the temperature impression of the materials aided identification (see further below). When surface irregularities or bumps were large enough to be registered by the pressure sense, such as with raised Braille characters, Ss moved the hand in slow sweeps, in contrast with the fast passes made in gauging roughness (p. 111).

That vibrations did occur when Ss' fingers swept over the materials is attested to by the need to stop up the Ss' ears to keep out telltale noises (pp. 123, 227). Recognition and discrimination were almost as good when Ss ran a pencil, rather than their fingertips, over the material. Performance was greatly disrupted, though, when Katz swaddled the pencil in felt or cloth to damp the transmitted vibrations (p. 108). When questioned, Ss said that the vibration feeling in the fingers and hand provided the basis for their judgments (p. 107).

Recognition performance dipped very little, and much less than one would expect if pressure sensation played a major role, when Katz coated Ss' fingers with a $0.1-\mathrm{mm}$ layer of collodium or a $0.2-\mathrm{mm}$ layer of leucoplast (pp. 98-99, 229-230). The collodium fills in irregularities on the skin surface, thus perhaps excluding the pressure sense (p. 234), yet only slightly dampens the vibrations, producing slightly "deaf" fingers. The collodium layer transforms the felt impression so that, when each hand feels a different surface, the surfaces are discriminated better if both hands are coated, or both are uncoated, than if one is uncoated and the other coated (pp. 101, 104). Katz likened the effect of the coating to the veiling effect of an episcotister (p. 100).

Subjects could even discriminate fairly well among such materials as wood, porcelain, metal, and paper, by hitting these materials with a hammer (p. 225). Even when the hammer was in contact with an iron plate for barely 3 to $5 \mathrm{msec}$, the blow and the resulting vibrations nevertheless produced confident recognition of the material.

In making a case for a distinct vibration sense, Katz attempted to exclude any possibility that the perception of roughness and the recognition of a material might be due to the resistance it offered the moving hand. Katz glued two sheets of different texture back-to-back, and then ran one hand down the composite sheet, with thumb on one side and index and middle fingers on the other. He clearly perceived two different impressions at the same time (p. 95). Katz concluded that the feeling of resistance in the hand is irrelevant to the judgment of roughness. Two other demonstrations are worth noting. Applying sticky glue to the fingers increased the experience of resistance, yet made all papers feel very smooth, because no vibrations were produced (pp. 113-115). The lack of vibrations was confirmed by the lack of noise when the ear was brought close to the touched surface. Cooling "deafened" the fingers, rendering Ss incapable of discriminating between some papers or recognizing some materials; such a loss indicates that the impression of roughness does not depend exclusively on the $S$ 's expenditure of force in moving the touch organ (p. 127).

A middle range of hand speed gave the best performance (p. 97), but Ss by no means maintained a constant speed. If moving the hand faster produces a higher "pitched" vibration, then to maintain a constant impression of a material over different hand speeds, the $S$ must take simultaneous account of "pitch" and hand speed. Katz wrapped a long strand of wire around a pencil, so that the successive loops of wire formed a series of ridges, and had Ss move their fingers, at different speeds, over the ridges. Judgments on roughness remained essentially the same 
over a tenfold range in speed $(1-10 \mathrm{~cm} / \mathrm{sec})$ (pp. 231-232).

Katz concedes that sometimes, such as when the bumps are high on the surface, pressure sensations may influence judgments on roughness to a large extent. He also notes, from his own experience, that vibration sensations have little part in the impression produced by broken-up materials, such as sand, sugar, and meal. And the pressure sense may aid the fair discrimination obtained when the fingers are moved above and then down onto a material (pp. 85-86). Increasing the intensity changes the pressure impression qualitatively; Katz cites Titchener, who described how, as the pressure grows, the sensation furst is bright, then becomes heavier and more fixed, and finally takes on a grain-like feel (pp. 22-25).

\section{THE TEMPERATURE SENSE}

But Katz considers the temperature sense, not the pressure sense, the second most important source of tactile information, after vibration. In addition to investigating systematically how the temperature sense leads to identification of materials, Katz noted other facets. Turning your head in front of a hot oven, for example, leads to localization of the heat source, which may take on a gestalt quality similar to voluminousness (p. 183). The superiority of blind persons at localizing objects through the temperature sense (e.g., they feel the approach of a warm cylinder at three times the distance that a normal person does) suggests that such a heightened capacity very probably participates in the so-called sixth sense of the blind (p. 184).

A material's ability to conduct heat represents the same type of invariant property as its ability to reflect light (albedo or reflectance) (p. 164). Metals feel positively cold. And wools feel positively warm, even though wool only rises to the body temperature if it is initially below (p. 165). In one task, blindfolded Ss were able to order materials, which had about the same specific warmth, in a series according to differences in their heat conductances (pp. 167-168). Recognition of such materials as glass and metal was markedly disrupted by artificially heating these materials (p. 137).

The temperature sense aids more in identifying characteristically cold materials, perhaps because such materials are relatively rare (pp. 173-174). In any case, shortening the duration of contact impedes recognition more for cold than for warm materials (pp. 172-173). Also, Ss made larger movements over the cold materials, as though to sharpen the sensation of cold (p. 176).

A buffer medium between the skin and an object, while letting vibrations through, may seriously disrupt the temperature sensation and thereby destroy the liveliness of the touch impression (p. 173). Katz believes the resulting dead, stiff feeling may explain why amputees often prefer to touch things with the bare stump rather than by means of an artificial device.

The temperature gestalt of a material depends in part on its capacity to absorb heat. If the material takes an unusual form (e.g., tin foil), an anomalous temperature gestalt may arise (pp. 179-180). The temperature sense is in part a distance sense, since a person may form a temperature impression of a material that is felt through a thin layer of another substance (p. 180).

In concluding this review, let me cite some miscellaneous findings, to show how little escaped Katz's attention. Katz observed that the pressure sense is not necessary for the impression of elasticity, since one can feel the elasticity of a rubber band by crunching it between the teeth. He regards the articular or muscle sense as the chief participant in the feeling of elasticity (pp. 65, 250). Unlike the case of object perception, in which no trace of movement persists, for Katz something elastic could not be imagined without also imagining a movement being carried out on the elastic object (p. 67).

When his Ss attempted to discriminate papers that differed in thickness, Katz found very small difference limens for his thinnest sheets and very large ones for the thicker sheets, but, more interestingly, he also found three qualitatively different stages in the judging process as a $S$ compared thicker and thicker sheets (pp. 148-149). With the thinnest sheets, the sheet served rather as a thin veil, through which the fingers felt each other; a difference in the thickness of such a "veil" could be easily detected. With intermediate thicknesses, the major clue was the flexibility and the way in which the sheets bent. With the thickest sheets, which bent little, the $S$ was finally forced to differentiate sheets by how far apart his fingers felt, a rather imprecise piece of information.

Vision dominates touch, when the two are in conflict (see above), and vision likely influences touch even in a normal situation. Katz found that some quite different materials, such as certain types of kid leather, cloth, rubber, and paper, may be readily confused when felt by a blindfolded person, indicating that vision, not touch, makes these items "feel" different in everyday life (p. 138). Katz also found that recognition through touch could be made considerably easier by allowing Ss a fleeting glimpse beforehand of the objects present (pp. 50, 132).

\section{REFERENCES}

ARNHEIM, R. David Katz, 1884-1953. American Journal of Psychology, 1953, 66, 638-642.

BÉKÉSY, G. v. Sensory inhibition. Princeton: Princeton University Press, 1967.

GELDARD, F. A. Cutaneous channels of communication. In W. A. Rosenblith (Ed.), Sensory communication. New York: Wiley, 1961. Pp. 73-87.

GELDARD, F. A. Cutaneous coding of optical signals: The optohapt. Perception \& Psychophysics, 1966, 1, 377-381.

GELDARD, F. A. Body English. Psychology Today, December 1968, 2, 42-47.

GIBSON, J. J. Adaptation, aftereffect, and contrast in the perception of curved lines. Journal of Experimental Psychology, 1933, 16, 1-31.

GIBSON, J. J. The senses considered as perceptual systeme. Boston: Hough ton Mifflin 1966.

HAY, J. C., PICK, H. L., JR., \& IKEDA, K. Visual capture produced by prism spectacles. Psychonomic Science, 1965, 2, 215-216.

KATZ, D. Der Aufbau der Tastwelt. Zeitschrift für Psychologie, 1925, Ergănzungsband 11, $270 \mathrm{pp}$.

KATZ, D. The world of colour. (Transl. by R. B. MacLeod and C. W. Fox) London: Kegan Paul, Trench, Trubner, 1935.

MacLEOD, R. B. David Katz, 1884-1953. Psychological Review, 1954, 61, 1-4.

ROCK, I., \& HARRIS, C. S. Vision and touch. Scientific American, May 1967, 216, 96-104.

\section{NOTES}

1. Preparation of this review was supported by a predoctoral traineeship from the U.S. Public Health Service, National Institute of General Medical Sciences, 5 T01 GM01011-07, to Harvard University.

2. Address: Department of Psychology, City College of CUNY, New York, New York 10031.

(Accepted for publication September 30, 1969.) 